Pacific Journal of Mathematic 


\title{
COLLECTIVELY COMPACT SETS OF LINEAR OPERATORS
}

\author{
P. M. Anselone and T. W. Palmer
}

\begin{abstract}
A set of linear operators from one normed linear space to another is collectively compact if and only if the union of the images of the unit ball has compact closure. This paper concerns general properties of such sets. Several useful criteria for sets of linear operators to be collectively compact are given. In particular, every compact set of compact linear operators is collectively compact. As a partial converse, every collectively compact set of self adjoint or normal operators on a Hilbert space is totally bounded.
\end{abstract}

Let $X$ and $Y$ be real or complex normed linear spaces and $[X, Y]$ the space of bounded linear operators on $X$ into $Y$. It is assumed that $[X, Y]$ has the norm topology except in Proposition 2.1(c), where a strong closure appears.

Let $\mathscr{B}$ denote the closed unit ball in $X$. Then $\mathscr{K} \subset[X, Y]$ is collectively compact if and only if the set $\mathscr{K} \mathscr{B}=\{K x: K \in \mathscr{K}$, $x \in \mathscr{B}\}$ has compact closure in $Y$. Collectively compact sets and their applications to integral equations have been treated in a number of papers [1-5, 7-9, 11-12]. Results obtained in this paper are used in a sequel [6] which relates spectral properties of operators $T$ and $T_{n}$, $n=1,2, \cdots$, such that $T_{n} \rightarrow T$ strongly and $\left\{T_{n}-T\right\}$ is collectively compact.

Frequently it will be necessary to show that a set in $Y$ or $[X, Y]$ is compact. For this purpose, recall that a subset of a metric space is compact if and only if it is closed and sequentially compact if and only if it is complete and totally bounded (for each $\varepsilon>0$ it has a finite $\varepsilon$-net). An often useful fact is that a set is totally bounded whenever it has a totally bounded $\varepsilon$-net for each $\varepsilon>0$. The familiar proposition that a continuous function from one topological space to another maps compact sets onto compact sets will be used several times. The following generalization of the Arzelà-Ascoli theorem will be needed.

LEMMA 1.1. Let $\mathfrak{F}$ be an equicontinuous set of functions from a compact metric space $\mathscr{K}$ into a metric space. For each $p \in \mathscr{K}$, assume that the set $\mathfrak{F} p=\{f(p): f \in \mathscr{K}\}$ has compact closure. Then the set $\mathfrak{F} \mathscr{K}=\{f(p): f \in \mathfrak{F}, p \in \mathscr{K}\}$ has compact closure.

2. General properties of collectively compact sets. Collectively compact sets of operators have a number of properties analogous to 
those of sets with compact closure in arbitrary normed linear spaces. For example, any subset or scalar multiple of a collectively compact set is collectively compact. Any finite union or sum of collectively compact sets is collectively compact. A collectively compact set is necessarily bounded.

Proposition 2.1. Let $\mathscr{K} \subset[X, Y]$ be collectively compact. Then the following sets are collectively compact:

(a) The convex hull of $\mathscr{K}$;

(b) The circled hull $\{\lambda K:|\lambda| \leqq 1, K \in \mathscr{K}\}$ of $\mathscr{K}$;

(c) The strong closure $\overline{\mathscr{K}}^{3}$ and norm closure $\overline{\mathscr{K}}$ of $\mathscr{K}$;

(d) $\left\{\sum_{n=1}^{N} \lambda_{n} K_{n}: K_{n} \in \mathscr{K}, \sum_{n=1}^{N}\left|\lambda_{n}\right| \leqq b_{;}^{\prime}\right.$ for each $b>0, N \leqq \infty$.

Proof. Mazur's theorem [10, p. 416] yields (a). The circled hull of a compact set in $Y$ is compact since the map $f$ defined by $f(\lambda, y)=\lambda y$ is continuous. This yields (b). Since $\overline{\mathscr{K}} \subset \overline{\mathscr{K}}^{s}$ and $\overline{\mathscr{K}}^{s} \mathscr{B} \subset \overline{\mathscr{K} \mathscr{B}}$, (c) is valid. Since $\mathscr{K}$ is bounded, the set in (d) belongs to the norm closure of the convex circled hull of $b \mathscr{K}$.

The next result involves integrals of operator valued functions. Let $\Gamma$ be a finite interval if $X$ is real and a rectifiable arc if $X$ is complex. Suppose $K_{\alpha}(\lambda) \subset[X, Y]$ for $\lambda \in \Gamma$ and $\alpha$ in an index set $A$. For each $\alpha \in A$ assume that $\int_{\Gamma} K_{\alpha}(\lambda) d \lambda$ is the strong or norm limit of the usual approximating sums,

$$
\sum_{j=1}^{m} K_{\alpha}\left(\lambda_{j}^{\prime}\right)\left(\lambda_{j}-\lambda_{j-1}\right) .
$$

Proposition 2.2. With the foregoing notation, assume that $\left\{K_{\alpha}(\lambda)\right.$ : $\alpha \in A, \lambda \in \Gamma\}$ is collectively compact. Then $\left\{\int_{\Gamma} K_{\alpha}(\lambda) d \lambda: \alpha \in A\right\}$ is collectively compact.

Proof. This follows from Proposition 2.1(c), (d) and

$$
\sum_{j=1}^{m}\left|\lambda_{j}-\lambda_{j-1}\right| \leqq \text { length }(\Gamma) \text {. }
$$

For the next proposition, let $Z$ be another normed linear space.

Proposition 2.3. Let $\mathscr{K} \subset[X, Y], \mathscr{K} \subset[Z, X]$ and $\mathscr{N}^{\prime} \subset[Y, Z]$. Then

(a) $\mathscr{K}$ collectively compact, $\mathscr{K}$ bounded $\Rightarrow \mathscr{K}$ Il collectively compact,

(b) $\mathscr{K}$ collectively compact, $\overline{\mathscr{N}}$ compact $\Rightarrow \mathscr{N} \mathscr{K}$ collectively compact. 
Proof. (a) Suppose $\|M\|<r$ for all $M \in$. $/$. Then

$$
\mathscr{K} \mathscr{H} \mathscr{B} \subset \boldsymbol{r} \mathscr{K} \mathscr{B},
$$

so $\overline{\mathscr{K} C \mathscr{C} \mathscr{S}}$ is compact and $\mathscr{K} \cdot \mathscr{C l}$ is collectively compact. (b) Define a map $f: \overline{\mathscr{N}} \times \overline{\mathscr{K} \mathscr{B}} \rightarrow Z$ by $f(N, y)=N y$ for $N \in \overline{\mathscr{V}}, y \in \overline{\mathscr{K} \mathscr{S}}$. Since $\overline{\mathscr{V}}$ and $\overline{\mathscr{K} \mathscr{S}}$ are compact and $f$ is continuous, its range, which contains $\mathscr{K} \mathscr{K}$, is compact. Thus $\overline{\mathscr{N} \mathscr{K} \mathscr{B}}$ is compact and $\mathscr{N} \mathscr{K}$ is collectively compact.

A collectively compact set is a bounded set of compact operators. The converse fails as can be seen by considering the set of one dimensional projections of norm one in any infinite dimensional Banach space. However we have:

THEOREM 2.4. Every compact set $\mathscr{K}$ of compact operators in $[X, Y]$ is collectively compact.

Proof. Define maps $f_{x}: \mathscr{K} \rightarrow Y$ by $f_{x}(K)=K x$ for $K \in \mathscr{K}, x \in \mathscr{B}$ and let $\mathfrak{F}=\left\{f_{x}: x \in \mathscr{B}\right\}$. Since $\left\|f_{x}\left(K_{1}-K_{2}\right)\right\| \leqq\left\|K_{1}-K_{2}\right\|$, $\mathfrak{F}$ is equicontinuous. Since each $K \in \mathscr{K}$ is compact, the sets $\overline{\Im \zeta K}=\overline{K \mathscr{S}}$ are compact. By hypothesis, $\mathscr{K}$ is compact. Therefore, by Lemma 1.1, $\overline{\mathscr{F} \mathscr{K}}=\overline{\mathscr{K} \mathscr{B}}$ is compact and $\mathscr{K}$ is collectively compact.

THEOREM 2.5. If $Y$ is complete, then every totally bounded set $\mathscr{K}$ of compact operators in $[X, Y]$ is collectively compact.

Proof. In this case, $\overline{\mathscr{K}}$ is a compact set of compact operators. By Theorem 2.4, $\overline{\mathscr{K}}$ is collectively compact. Hence, $\mathscr{K}$ is collectively compact.

The converses of Theorems 2.4 and 2.5 are false:

EXAMPLE 2.6. Let $\mathscr{K}$ be the set of operators on $l^{p}(1 \leqq p \leqq \infty)$ defined by $K_{n} x=x_{n} \varphi_{1}, n \geqq 1$. Since $\mathscr{K} \mathscr{B}$ is bounded and onedimensional, $\mathscr{K}$ is collectively compact. But $\mathscr{K}$ is not totally bounded, for $\left\|K_{m}-K_{n}\right\|=2^{1 / p}$ if $m \neq n$.

Partial converses of Theorem 2.5 are given in the next section.

3. Operators on a Hilbert space. Throughout this section, let $X$ be a Hilbert space. It will be shown that every collectively compact set of self adjoint or normal operators in $[X, X]$ is totally bounded.

We begin by considering sets of projections. Let $\mathscr{S}=\{x:\|x\|=1\}$ and, for each $x \in \mathscr{S}$, let $E_{x}$ be the self adjoint projection onto the subspace spanned by $x$. 
Lemma 3.1. Let $\mathscr{U} \subset \mathscr{S}$ and $\mathscr{C l}=\left\{E_{x}: x \in \mathscr{U}\right\}$. (Thus, $\mathscr{C l}$ can be any set of self adjoint projections with one-dimensional ranges.) The following statements are equivalent:

(a) $\mathscr{C}$ is totally bounded;

(b) - $/$ is is totally bounded;

(c) Ml is collectively compact.

Proof. Since $E_{x} y=(y, x) x$ for $y \in X$ and $x \in \mathscr{S}$, the map $f$ : $\mathscr{S} \rightarrow[X, X]$ given by $f(x)=E_{x}$ is continuous. Since $\mathscr{C l}=f(\mathscr{U})$, (a) implies (b). By Theorem 2.5, (b) implies (c). Since $\mathscr{C} \subset \mathscr{L} \mathscr{\mathscr { B }}$, (c) implies (a).

LEMMA 3.2. Let _th be a collectively compact set of self adjoint projections and ' $\mathscr{C}^{\prime}$ any subset consisting of mutually orthogonal projections. Then ' $\mathbb{C l}^{\prime}$ is finite and there is an integer $n$, independent of $\mathbb{C l}^{\prime}$, such that

$$
\sum_{E \in, \mathbb{H}^{\prime}} \operatorname{dim} E X \leqq n
$$

Proof. Since $\mathscr{C} \mathscr{S}$ is totally bounded, it can be covered by a finite number $n$ of open balls of radius 1/2. If $x, y \in \mathscr{C l} \mathscr{S}$ and $x \perp y$ then $\|x-y\|=\sqrt{2}$, so that $x$ and $y$ lie in different balls. The lemma follows.

Lemma 3.3. Suppose $X$ is a real Hilbert space and $\hat{X}$ is its complexification defined in the usual way. For $\mathscr{K} \subset[X, X]$, let $\hat{\mathscr{K}} \subset[\hat{X}, \hat{X}]$ be the set of canonical extensions of operators in $\mathscr{K}$. Then $\mathscr{\mathscr { K }}$ is collectively compact if and only if $\hat{\mathscr{K}}^{\text {is collectively }}$ compact.

Since the proof is straightforward, it is omitted.

We are now ready to establish the principal results of this section.

THEOREM 3.4. Let $\mathscr{K}$ be a set of self adjoint or normal compact operators on a Hilbert space. Then the following statements are equivalent:

(a) $\mathscr{K}$ is collectively compact.

(b) $\mathscr{K}^{*}=\left\{K^{*}: K \in \mathscr{K}\right\}$ is collectively compact.

(c) $\mathscr{K}$ is totally bounded.

Proof. Without loss of generality, $X$ is complex. Assume

$$
\mathscr{L}=\left\{K_{\alpha}: \alpha \in A\right\}
$$

collectively compact. Then every $K_{\alpha}$ is compact. For each $\alpha \in A$, 
the spectral theorem yields a decomposition

$$
K_{\alpha}=\sum_{n} \lambda_{\alpha n} E_{\alpha n}
$$

with the self adjoint projections $E_{\alpha n}$ multually orthogonal and with $\operatorname{dim} E_{\alpha n} X=1$ (thus, the $\lambda_{\alpha n}$ are not necessarily distinct). Since $\mathscr{K}$ is bounded, there exists $b<\infty$ such that

$$
\left|\lambda_{\alpha n}\right| \leqq\left\|K_{\alpha}\right\| \leqq b, \quad \alpha \in A, n \geqq 1 .
$$

For $\alpha \in A$ and $\varepsilon>0$, let

$$
\begin{aligned}
N_{\alpha \varepsilon} & =\left\{n:\left|\lambda_{\alpha n}\right| \geqq \varepsilon\right\}, \\
\mathscr{C}_{\varepsilon} & =\left\{E_{\alpha n}: \alpha \in A, n \in N_{\alpha \varepsilon}\right\}, \\
K_{\alpha \varepsilon} & =\sum_{n \in N} \lambda_{\alpha n} E_{\alpha n}, \\
\mathscr{K}_{\varepsilon} & =\left\{K_{\alpha \varepsilon}: \alpha \in A\right\} .
\end{aligned}
$$

Then $K_{\alpha} E_{\alpha n}=\lambda_{\alpha n} E_{\alpha n}$ and, for $n \in N_{\alpha \varepsilon}, E_{\alpha n} \mathscr{\mathscr { B }}=\lambda_{\alpha n}^{-1} K_{\alpha} E_{\alpha n} \mathscr{B} \subset \varepsilon^{-1} K_{\alpha} \mathscr{B}$. Therefore, $\mathscr{C}_{\varepsilon} \mathscr{B} \subset \varepsilon^{-1} \mathscr{K} \mathscr{B}$ and $\mathscr{C}_{\varepsilon}$ is collectively compact. By Lemma 3.1, $\mathscr{L}_{\varepsilon}$ is totally bounded. By Lemma 3.2, there exists $n$ such that, ior each $\alpha \in A, N_{\alpha \varepsilon}$ contains no more than $n_{\varepsilon}$ elements Then $\mathscr{K}_{\varepsilon}$ is in the convex circled hull of $b n_{\varepsilon} \mathscr{L}_{\varepsilon}$, so $\mathscr{K}_{\varepsilon}$ is totally bounded. Since $\left\|K_{\alpha}-K_{\alpha \varepsilon}\right\|<\varepsilon$ for all $\alpha \in A$, $\mathscr{K}_{\varepsilon}$ is an $\varepsilon$-net for $\mathscr{K}$. Therefore, $\mathscr{K}$ is totally bounded.

This result and Theorem 2.5 give:

$\mathscr{K}$ collectively compact if and only if $\mathscr{K}$ totally bounded

Since $\left\|T^{*}\right\|=\|T\|$ for all $T \in[X, X]$,

$\mathscr{K}$ totally bounded if and only if $\mathscr{K}^{*}$ totally bounded.

The theorem follows.

THEOREM 3.5. Let $\mathscr{K}$ be a set of compact operators on a Hilber space. Then $\mathscr{K}$ is totally bounded if and only if both $\mathscr{K}$ and $\mathscr{K}$ : are collectively compact.

Proof. As above, $\mathscr{K}$ totally bounded implies $\mathscr{K}$ and $\mathscr{K}^{*}$ col lectively compact. Now assume $\mathscr{K}$ and $\mathscr{K}^{*}$ collectively compact Then the sets

$$
\mathscr{R}=\left\{K+K^{*}: K \in \mathscr{K}\right\}, \quad \mathscr{J}=\left\{K-K^{*}: K \in \mathscr{K}\right\}
$$

are collectively compact. By Theorem $3.4, \mathscr{R}$ and $\mathscr{I}$ are totall: bounded. Since $\mathscr{K} \cup \mathscr{K}^{*} \subset(\mathscr{R}+\mathscr{I}) \cup(\mathscr{R}-\mathscr{I})$, both $\mathscr{K}$ an $\mathscr{K}^{*}$ are totally bounded. 
For the collectively compact set $\mathscr{K}$ in Example 2.6 with $p=2$, it is easily verified that $\mathscr{K}^{*}$ is not collectively compact. This also follows from Theorem 3.5, since $\mathscr{K}$ is not totally bounded.

\section{REFERENCES}

1. P. M. Anselone, "Convergence and error bounds for approximate solutions of integral and operator equations." Error in Digital Computation, Vol. 2, ed. by L. B. Rall, Wiley, 1965.

2. Uniform approximation theory for integral equations with discontinuous kernels, SIAM J. Num. Anal. 4 (1967), 245-253.

3. - Perturbations of collectively compact operator sequences, J. Math. Anal. Appl., to appear.

4. P. M. Anselone and J. M. Gonzalez-Fernandez, Uniformly convergent approximate solutions of Fredholm integral equations, J. Math. Anal. Appl. 10 (1965), 519-536.

5. P. M. Anselone and R. H. Moore, Approximate solutions of integral and operator equations, J. Math. Anal. Appl. 9 (1964), 268-277.

6. P. M. Anselone and T. W. Palmer, Spectral analysis of collectively compact, strongly convergent operator sequences, Pacific J. Math. 25 (1968), 423-431.

7. K. E. Atkinson, The numerical solution of Fredholm linear integral equations of the second kind, SIAM J. Num. Anal. (to appear).

8. - The solution of non-unique linear integral equations, Numerische Math. (to appear).

9. The numerical solution of the eigenvalue problem for compact integral operators, Trans. Amer. Math. Soc. 129 (1967), 458-465.

10. N. Dunford and J. T. Schwartz, Linear Operators, Part I, Interscience, 1958.

11. R. H. Moore, Differentiability and convergence for compact nonlinear operators, J. Math. Anal. Appl. 16 (1966), 65-72.

12. - Approximations to Newton's method and nonlinear operator equations (submitted for publication).

Received February 27, 1967. Sponsored by the Mathematics Research Center, U.S. Army, Madison, Wisconsin, under Contract No.: DA-31-124-ARO-D-462.

Jregon State University, CoRvallis

UNIVERSITY OF KANSAS, LAWRENCE 


\title{
PACIFIC JOURNAL OF MATHEMATICS
}

\author{
EDITORS
}

\section{H. ROYDEN}

Stanford University

Stanford, California

\author{
J. P. JANS \\ University of Washington \\ Seattle, Washington 98105
}

\section{J. DugundJI}

Department of Mathematics

University of Southern California

Los Angeles, California 90007

\section{RICHARD ARENS}

University of California

Los Angeles, California 90024

\section{ASSOCIATE EDITORS}
E. F. BECKENBACH
B. H. NEUMANN
F. WOLF
K. YOSIDA

\section{SUPPORTING INSTITUTIONS}

\author{
UNIVERSITY OF BRITISH COLUMBIA \\ CALIFORNIA INSTITUTE OF TECHNOLOGY \\ UNIVERSITY OF CALIFORNIA \\ MONTANA STATE UNIVERSITY \\ UNIVERSITY OF NEVADA \\ NEW MEXICO STATE UNIVERSITY \\ OREGON STATE UNIVERSITY \\ UNIVERSITY OF OREGON \\ OSAKA UNIVERSITY \\ UNIVERSITY OF SOUTHERN CALIFORNIA
}

\author{
STANFORD UNIVERSITY \\ UNIVERSITY OF TOKYO \\ UNIVERSITY OF UTAH \\ WASHINGTON STATE UNIVERSITY \\ UNIVERSITY OF WASHINGTON \\ AMERICAN MATHEMATICAL SOCIETY \\ CHEVRON RESEARCH CORPORATION \\ TRW SYSTEMS \\ NAVAL WEAPONS CENTER
}

Mathematical papers intended for publication in the Pacific Journal of Mathematics should be in typed form or offset-reproduced, double spaced with large margins. Underline Greek letters in red, German in green, and script in blue. The first paragraph or two must be capable of being used separately as a synopsis of the entire paper. It should not contain references to the bibliography. Manuscripts, in duplicate if possible, may be sent to any one of the four editors. All other communications to the editors should be addressed to the managing editor, Richard Arens, University of California, Los Angeles, California 90024.

Each author of each article receives 50 reprints free of charge; additional copies may be obtained at cost in multiples of 50 .

The Pacific Journal of Mathematics is published monthly. Effective with Volume 16 the price per volume (3 numbers) is $\$ 8.00$; single issues, $\$ 3.00$. Special price for current issues to individual faculty members of supporting institutions and to individual members of the American Mathematical Society: $\$ 4.00$ per volume; single issues $\$ 1.50$. Back numbers are available.

Subscriptions, orders for back numbers, and changes of address should be sent to Pacific Journal of Mathematics, 103 Highland Boulevard, Berkeley 8, California.

Printed at Kokusai Bunken Insatsusha (International Academic Printing Co., Ltd.), 7-17, Fujimi 2-chome, Chiyoda-ku, Tokyo, Japan.

PUBLISHED BY PACIFIC JOURNAL OF MATHEMATICS, A NON-PROFIT CORPORATION

The Supporting Institutions listed above contribute to the cost of publication of this Journal, but they are not owners of publishers and have no responsibility for its content or policies. 


\section{Pacific Journal of Mathematics}

\section{Vol. 25, No. $3 \quad$ November, 1968}

Philip Marshall Anselone and Theodore Windle Palmer, Collectively

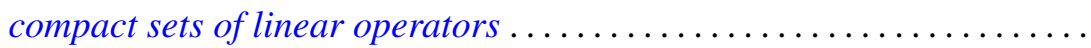

Philip Marshall Anselone and Theodore Windle Palmer, Spectral analysis of collectively compact, strongly convergent operator sequences.........

Edward A. Bender, Characteristic polynomials of symmetric matrices...... 433

Robert Morgan Brooks, The structure space of a commutative locally convex

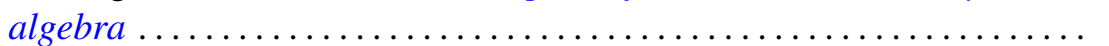

Jacob Feldman and Frederick Paul Greenleaf, Existence of Borel

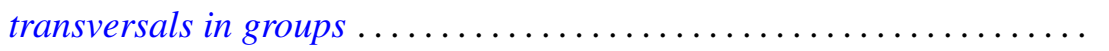

Thomas Muirhead Flett, Mean values of power series 463

Richard Vernon Fuller, Relations among continuous and various

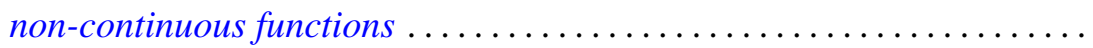

Philip Hartman, Convex sets and the bounded slope condition ............

Marcel Herzog, On finite groups containing a CCT-subgroup with a cyclic Sylow subgroup .

James Secord Howland, On the essential spectrum of Schroedinger

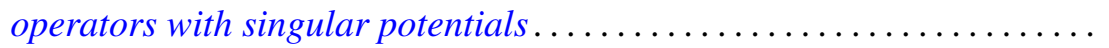

Thomas William Hungerford, On the structure of principal ideal rings .....

Paul Joseph Kelly and Ernst Gabor Straus, Curvature in Hilbert geometries. II mpati Madhusudana Rao, Linear functionals on Orlicz spaces:

Malempati Madhusudana Rao, Linear functionals on Orli
$\quad$ General theory............................
Stanley F. Robinson, Theorems on Brewer sums.......
Ralph Tyrrell Rockafellar, A general correspondence betw

Malempati Madhusudana Rao, Linear functiona
$\quad$ General theory.........................
Stanley F. Robinson, Theorems on Brewer sums
Ralph Tyrrell Rockafellar, A general corresponden

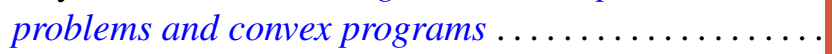

Richard Benjamin Sher, Defining subsets of $E^{3}$ by cubes.

Howard Jacob Weiner, Invariant measures and Cesàro summability... 